\title{
Electricity Tariff Design in the Context of an Ambitious Green Transition
}

\author{
Nicolás Morell, José Pablo Chaves, Tomás Gómez \\ Instituto de Investigación Tecnológica \\ Universidad Pontificia Comillas, Madrid, Spain
}

\begin{abstract}
Current tariff designs do not incentivize efficient or equitable responses by active customers adopting renewable self-generation or providing flexibility in a future fully decarbonized electricity system. This chapter revises current practices in Europe and, based on the revisited principles of efficiency and equity, proposes a first benchmark for tariff design. Forward-looking peak-coincident network charges that reflect network incremental costs and fixed charges that collect residual network costs and policy costs are recommended. No one-size-fits-all model exists, in practice. These are guidelines for regulators when dealing with the trade-offs between the tariff legacy and the new requirements imposed by this energy transition.
\end{abstract}

KEYWORDS: Electricity Tariffs, Decarbonization, Network Tariffs, Active Customer Response, Distributed Energy Resources

\section{INTRODUCTION}

Traditionally, electricity tariffs have evolved in parallel with the organization and regulation of electricity systems. From integral tariffs based on bundled services and costs under vertically integrated utilities, regulated as monopolies, to unbundled energy prices freely negotiated in electricity markets and regulated network and other policy charges (Pérez-Arriaga, 2013).

Nowadays, electricity systems are entering a new transition period, caused by three major drivers, in the following referred to as the 3-D's: digitalization, decarbonization, and decentralization.

Decentralization and digitalization are putting consumers at the centre of the energy transition. New technologies are available to the end-users, which allow them to change the way they consume, self-produce, or store electricity. These technologies include: 1 ) thermostatically controlled loads, including heat pumps, 2) distributed renewable generation, 3) energy storage, 4) electric vehicles (EVs), and 5) smart meters and other information and communication technologies (ICT). Current electricity tariff designs are not suited to cope with these changes, provoking distorting effects in the efficiency of the system. The individual benefits obtained by consumers responding to actual tariffs are not always bringing associated system benefits, and in addition, may provoke distributional and non-equitable effects for some customer categories.

On the other hand, electricity systems are required to be fully decarbonized over the next few decades. To achieve this, market conditions need to attract investments in renewable energy and in flexibility re- sources like energy storage, that can compensate for variable electricity production. Tariffs and market prices must also provide the right incentives for consumers to become active market participants, providing flexibility and contributing to stabilizing the electricity system.

Due to these changes, we need to rethink electricity system regulation, and specifically traditional electricity tariffs. Nevertheless, promoting the technical and economic efficiency of the electricity system should remain the principle aim of electricity tariffs, in order to achieve a fair and equitable allocation of costs and charges to network users. This objective must be fulfilled acknowledging the capability of network users to respond to economic signals, their investments in distributed energy resources (DER). The future tariff should consider that network users may be producers, consumers, or active customers, with controllable loads, self-generation or storage technologies, which act as either consumers, producers or both.

Electricity prices and tariffs will therefore become a relevant instrument to guide an efficient and equitable transition towards a more decarbonized energy system.

The way tariffs fulfil this role in different electricity markets and countries differs significantly depending on which costs are recovered and which charges are used to recover them.

As an initial distinction, total costs can be divided into energy costs - determined by market mechanisms - transmission and distribution network costs, and policy costs, such as support for renewable energy sources (RES). All of these costs are recovered via the electricity bill along with applicable taxes. 
In Europe, wholesale and retail electricity markets are used to settle energy transactions between producers and consumers - or their market representatives, retailers and aggregators. Therefore, the allocation of energy costs to consumer bills is based on those electricity market prices. However, for the majority of small consumers, flat electricity prices do not reflect the variability of market prices, because they are based on the aggregated price over the month or year.

A question that arises is whether the actual market design is appropriate for a future $100 \%$ renewable electricity system, with an increasing share of solar and wind technologies, with high variability and intermittency of generation, and near zero marginal costs. The need to ensure supply adequacy and security under these circumstances is a challenge that should be addressed with regulatory instruments which incentivize investment in flexible technologies, such as storage systems, and in firm capacity resources (Gerres et al., 2019a). However, the main focus of this chapter is not on electricity market design changes to enable a high penetration of renewable generation, but rather the subsequent challenges of such a system transformation on network tariff design and the allocation of other regulated policy costs.

In Europe, regarding transmission and distribution costs allocated through regulated network charges, unbundled transmission system operators (TSOs) and distribution system operators (DSOs) are responsible for the operation, maintenance and investment of network infrastructures. TSOs and DSOs charge regulated tariffs to network users in order to recover the amount of network revenues allowed by National Regulatory Authorities (NRAs). NRAs oversee, and in most cases, decide on tariff setting. The emphasis of this chapter is mainly on distribution tariffs, but many of the discussed principles for tariff design may apply also to transmission tariffs.

NRAs design or approve tariff structures periodically in order to ensure there is a right balance between competing tariff principles, manage complex trade-offs between different tariff options and consider associated impacts on network users. While many leading tariff principles that were relevant in the past will remain so in the future, the balance between principles might shift in the context of a changing electricity system (CEER, 2020).
This chapter aims to explore the role of tariff design on the efficient development of the electricity system, putting special emphasis on the response of active customers in relation to investing in and managing DERs. Section 2 provides a general description of current tariff designs across Europe and, in some cases, new proposals and trends. Section 3 develops a theoretical framework on which electricity tariff design should be grounded, following the regulatory principles, while Section 4 elaborates on the impact of the 3-D's on current electricity tariffs. Sections 5 and 6 present an efficient and equitable approach to designing network and policy charges, respectively. To conclude, Section 7 provides examples of the benefits of employing efficient charges compared to commonly used charges with increasing penetration of DERs.

\section{NETWORK TARIFFS IN EUROPE: CURRENT PRACTICES}

Before analysing the current practices on tariff design in selected European countries, we introduce a common terminology to understand the involved concepts. That will facilitate the comparison between the different tariff alternatives and options.

Regulated costs can be allocated to network users through different types of charges. The most common type of charge is a volumetric or energy charge ( $€$ per $\mathrm{kWh}$ ). The second type of charge is a capacity charge ( $€$ per $\mathrm{kW}$ ), which can be differentiated between a maximum/ peak demand charge or a contracted capacity charge. While maximum demand charges are based on the individual measured peak consumption, contracted capacity charges are based on an agreed value that sets the maximum power that can be withdrawn by the user from the network. In some countries, modification of the contracted capacity can be requested by network users, with such requests being reviewed by DSOs and accepted under certain circumstances. Finally, a third type of charge is a fixed amount allocated to each network user ( $€$ per customer). Typically, these charges are billed to customers periodically, for instance every month or bimonthly.

\section{TABLE 1. TYPES OF CHARGES ACCORDING TO TIME BLOCKS AND PRICE SETTING PERIODICITY}

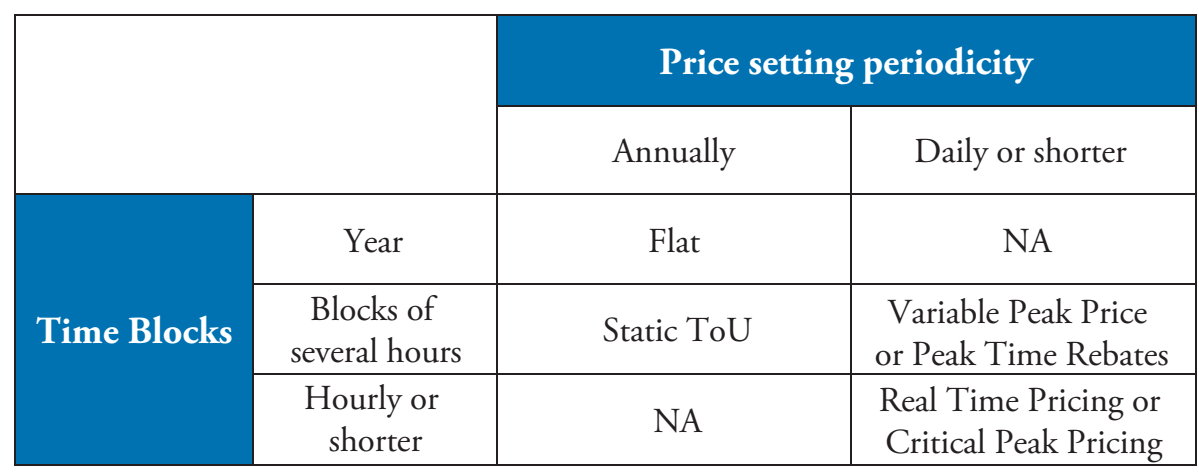

Note. Summarizes the different types of charges depending on time-blocks and price setting periodicity. Static tariffs updated every year correspond to flat or ToU charges, while dynamic tariffs, by design, require shorter time blocks, even hourly. 
TABLE 2. OVERVIEW OF NATIONAL REGULATION ON NETWORK TARIFFS

\begin{tabular}{|c|c|c|c|c|c|c|c|c|c|}
\hline \multirow[b]{2}{*}{ Country } & \multirow[b]{2}{*}{$\begin{array}{l}\text { Currently } \\
\text { in place }\end{array}$} & \multirow[b]{2}{*}{$\begin{array}{l}\text { Planned } \\
\text { reform }\end{array}$} & \multirow[b]{2}{*}{ Customer category } & \multicolumn{3}{|c|}{ Type of tariff charge } & \multicolumn{3}{|c|}{ Granularity } \\
\hline & & & & Fixed & Energy & Capacity & Locational & $\begin{array}{l}\text { ToU } \\
\text { energy }\end{array}$ & $\begin{array}{l}\text { ToU } \\
\text { capacity }\end{array}$ \\
\hline \multirow{3}{*}{$\begin{array}{l}\text { Belgium, Flanders } \\
\text { (EU-Universal project, } \\
\text { 2020) }\end{array}$} & $\mathrm{X}$ & & $\begin{array}{l}\text { Household and } \\
\text { small businesses }\end{array}$ & & $\mathrm{X}$ & & $\mathrm{X}$ & $\begin{array}{l}2 \text { time- } \\
\text { blocks }\end{array}$ & \\
\hline & $\mathrm{X}$ & & Large network users & & $\mathrm{X}$ & $\mathrm{X}$ & $\mathrm{X}$ & $\begin{array}{l}2 \text { time- } \\
\text { blocks }\end{array}$ & \\
\hline & & $\mathrm{X}$ & $\begin{array}{l}\text { Households and } \\
\text { small businesses }\end{array}$ & & $\mathrm{X}$ & $\mathrm{X}$ & $\mathrm{X}$ & & \\
\hline \multirow{3}{*}{ Denmark } & $\mathrm{X}$ & & Households & $\mathrm{X}$ & $\mathrm{X}$ & & $\mathrm{X}$ & $\mathrm{X}$ & \\
\hline & $\mathrm{X}$ & & $\begin{array}{l}\mathrm{LV}, \mathrm{MV} \text { industry } \\
\text { customers }\end{array}$ & $\mathrm{X}$ & $\mathrm{X}$ & & $\mathrm{X}$ & $\mathrm{X}$ & \\
\hline & $\mathrm{X}$ & & $\mathrm{JHV}$, industry customers & $\mathrm{X}$ & $\mathrm{X}$ & & $\mathrm{X}$ & $\mathrm{X}$ & \\
\hline \multirow{3}{*}{$\begin{array}{c}\text { France } \\
(\mathrm{CEER}, 2020)\end{array}$} & $\mathrm{X}$ & & LV customers $<36 \mathrm{kVA}$ & & $\mathrm{X}$ & $\mathrm{X}$ & & $\begin{array}{l}2 \text { time- } \\
\text { blocks } \\
2 \text { seasons }\end{array}$ & \\
\hline & $\mathrm{X}$ & & LV customers $>36 \mathrm{kVA}$ & & $\mathrm{X}$ & $\mathrm{X}$ & & $\begin{array}{l}2 \text { time- } \\
\text { blocks } 2 \\
\text { seasons }\end{array}$ & $\begin{array}{l}2 \text { periods } \\
2 \text { seasons }\end{array}$ \\
\hline & $\mathrm{X}$ & & MV, HV customers & $\mathrm{X}$ & $\mathrm{X}$ & & & $\begin{array}{l}2 \text { time- } \\
\text { blocks } \\
2 \text { seasons } \\
+1 \text { time- } \\
\text { block }\end{array}$ & $\begin{array}{l}2 \text { periods } \\
2 \text { seasons } \\
+1 \text { period }\end{array}$ \\
\hline \multirow{2}{*}{$\begin{array}{c}\text { Germany } \\
\text { (EU-Universal project, } \\
\text { 2020) }\end{array}$} & $\mathrm{X}$ & & $\begin{array}{c}\text { Customers at any } \\
\text { voltage level without } \\
\text { metering of load profiles }\end{array}$ & & $\mathrm{X}$ & $\mathrm{X}$ & $\mathrm{X}$ & & \\
\hline & $\mathrm{X}$ & & $\begin{array}{l}\text { Customers at any } \\
\text { voltage level with } \\
\text { metering of load profiles }\end{array}$ & $\mathrm{X}$ & $\mathrm{X}$ & $\mathrm{X}$ & $\mathrm{X}$ & & \\
\hline \multirow{2}{*}{$\begin{array}{c}\text { Italy } \\
\text { (CEER, 2020) } \\
\text { (Regalini, 2019) }\end{array}$} & $\mathrm{X}$ & & LV customers & $\mathrm{X}$ & $\mathrm{X}$ & $\mathrm{X}$ & & 2 periods & \\
\hline & & $\mathrm{X}$ & LV customers with EV & $\mathrm{X}$ & $\mathrm{X}$ & $\mathrm{X}$ & & 2 periods & 2 periods \\
\hline \multirow{3}{*}{$\begin{array}{c}\text { Norway } \\
\text { (CEER, 2020) }\end{array}$} & $\mathrm{X}$ & & LV customers $<100 \mathrm{~kW}$ & $\mathrm{X}$ & $\mathrm{X}$ & (X) & $\mathrm{X}$ & & \\
\hline & $\mathrm{X}$ & & $\begin{array}{l}\text { LV customers }>100 \mathrm{~kW} \text {, } \\
\text { and MV, HV customers }\end{array}$ & $\mathrm{X}$ & $\mathrm{X}$ & $\mathrm{X}$ & $\mathrm{X}$ & & \\
\hline & & $\mathrm{X}$ & LV customers $<100 \mathrm{~kW}$ & $\mathrm{X}$ & $\bar{X}$ & (X) & $\bar{X}$ & $\bar{X}$ & (X) \\
\hline \multirow{3}{*}{$\begin{array}{c}\text { Portugal } \\
\text { (EDP Distribuiçáo, } \\
\text { 2020); (ERSE, 2018) }\end{array}$} & $\mathrm{X}$ & & LV customers & & $\mathrm{X}$ & $\mathrm{X}$ & & $\begin{array}{l}1,2 \text { or } 3 \\
\text { time- } \\
\text { blocks }\end{array}$ & \\
\hline & $\mathrm{X}$ & & MV, HV customers & & $\mathrm{X}$ & $\mathrm{X}$ & & $\begin{array}{l}4 \text { time- } \\
\text { blocks } \\
2 \text { seasons }\end{array}$ & \\
\hline & & Pilot & $\begin{array}{c}\text { MV, HV, EHV } \\
\text { customers }\end{array}$ & & $\mathrm{X}$ & $\mathrm{X}$ & $\mathrm{X}$ & $\begin{array}{l}4 \text { time- } \\
\text { blocks }\end{array}$ & $\begin{array}{l}2 \text { periods } \\
3 \text { seasons }\end{array}$ \\
\hline \multirow{2}{*}{$\begin{array}{c}\text { Spain } \\
(\mathrm{CNMC}, 2020)\end{array}$} & & $\mathrm{X}$ & LV customers & & $\mathrm{X}$ & $\mathrm{X}$ & & $\begin{array}{l}3 \text { time- } \\
\text { blocks }\end{array}$ & 2 periods \\
\hline & & $\mathrm{X}$ & MV, HV customers & & $\mathrm{X}$ & $\mathrm{X}$ & & $\begin{array}{l}3 \text { time- } \\
\text { blocks } \\
4 \text { seasons }\end{array}$ & $\begin{array}{l}3 \text { periods } \\
4 \text { seasons }\end{array}$ \\
\hline \multirow{3}{*}{$\begin{array}{l}\text { The United Kingdom } \\
\text { (CEER, 2020) } \\
\text { (Ofgem, 2018) }\end{array}$} & $\mathrm{X}$ & & $\begin{array}{l}\text { Domestic and } \\
\text { small businesses }\end{array}$ & $\mathrm{X}$ & $\mathrm{X}$ & & $\mathrm{X}$ & $\begin{array}{l}1,2 \text { or } 3 \\
\text { time- } \\
\text { blocks }\end{array}$ & \\
\hline & $\mathrm{X}$ & & Large businesses & $\mathrm{X}$ & $\mathrm{X}$ & $\mathrm{X}$ & $\mathrm{X}$ & $\begin{array}{l}3 \text { time- } \\
\text { blocks }\end{array}$ & \\
\hline & & $\bar{X}$ & LV, MV, HV customers & $\mathrm{X}$ & $\mathrm{X}$ & $\bar{X}$ & $\bar{X}$ & $\mathrm{X}$ & $\mathrm{X}$ \\
\hline
\end{tabular}

Note. Source: EU-Universal project (2020). Shows an overview of current and planned distribution tariffs in some European countries. 
Energy and/or capacity charges can differ for each time block - the period when energy or maximum demand are measured and charge -during the billing period. This time block differentiation is known as time-of-use (ToU) charges, and typically it differentiates, at least, between peak and off-peak hours.

Additionally, tariffs differ by customer categories established by national regulation. For example, in Spain or France, charges vary depending on the voltage level at the connection point (CNMC, 2019). Other countries, like Belgium or the UK, differentiate among residential, business, and industrial customers.

Finally, tariffs can be characterized by the interval at which energy, capacity or fixed charges are adjusted. In broad terms, a differentiation is made between static tariffs, which are updated, for instance, annually, or dynamic tariffs that can be updated daily, or even at shorter notice.

The most advanced type of dynamic tariffs is real-time pricing (RTP), in which the charge would vary hourly or even by minutes, reflecting network utilization levels - similar to wholesale electricity market prices. In the case of critical peak pricing (CPP), the customer pays a higher price at specific times during the day, or on days during the year when network usage is very high or the grid is exceptionally constrained. Peak time rebates (PTR) reward the customer for reducing the load (Bhagwat and Hadush, 2020). Another kind of dynamic tariff is the Variable Peak Price (VPP), where consumers know peak time blocks in advance, but tariffs charged during those peak hours are indicated only a few hours before peak events.

While reducing the cost uncertainty for customers, flat tariffs do not provide incentives to customers to adjust their consumption to enable the most efficient network operation. With the energy transition and subsequent electrification (e.g. of heating and transport), such non-optimal behaviour can jeopardize efficient network operation, and ultimately result in additional network investment. Replacing flat charges by ToU charges is one option to incentivize efficient customer responses, by translating system peak-hours into high price time-blocks. Thanks to smart meter deployments in recent years, these trends have been observed in some of the selected countries that are described below (Abdelmotteleb et al., 2018; Passey et al., 2017; Pérez-Arriaga, 2016).

As shown, there is no one-size-fits-all model regarding network tariff design in Europe. Historical reasons and different policy objectives that NRAs aimed to achieve through tariff schemes mainly justify the observed alternatives. Network tariffs range from simple flat energy charges to more sophisticated structures with cost reflective capacity charges. Many countries are moving towards higher temporal granularity by introducing time-of-use charges. Some countries, such as Portugal, are also proposing locational charges among customers, and some other countries such as Germany and the UK are already applying locational differentiation because tariffs are not national and differ by DSO. Additionally, the deployment of smart meters in many European countries is creating new opportunities to design more granular network tariffs that would increase cost-reflectiveness for potentially price responsive active customers.

\section{REGULATORY PRINCIPLES FOR TARIFF DESIGN}

Traditionally, most regulators have preferred to design simple charges to allocate power system costs to electricity customers. This approach may become inadequate with increasing penetration of active customers with DERs and flexible demand. Such simple methods exhibit limited (if any) temporal or spatial granularity and result in tariffs that typically bundle costs of all the value that customers receive. So, tariffs could be over or undercompensating active customers for the system value they provide. As a result, customers may opt for investing in DERs, which maximize their own profit but are highly inefficient from the system's point of view. Moreover, innovative opportunities to provide additional services for operating the system are being left untapped by inadequate compensation as a consequence of traditional tariff designs. This reduces the overall efficiency of the system, since tariffs are unable to reveal and appropriately compensate the value that DERs and price-responsive demand can provide to the system (Pérez-Arriaga, 2016). This section sets the principles for electricity network tariff design, putting the emphasis on the relevant role that active customers would play in the energy transition.

Cost-recovery is the main principle guiding any tariff design. However, the aim of tariff design is not only to ensure cost-recovery but also to enhance the system's technical and economic efficiency, both in the short and in the long-term, by promoting the customers' efficient usage of the electricity system. In addition, charges should be fair and equitable among customer categories and non-discriminatory between customers that use the service in the same way. A general consensus exists in the literature that electricity tariffs should follow both economic efficiency and equity principles (Burger et al., 2019; OECD, 2011; Rodríguez Ortega et al., 2008).

\subsection{ECONOMIC EFFICIENCY}

Economic efficiency is based on the ideal principle that goods or services should be consumed by whoever benefits most from them (Pérez-Arriaga, 2013). The main objective of this principle is social welfare maximization, or in our case, total system cost minimization. Not only shortterm but also long-term system costs should be minimized. One way to incentivize system cost minimization, in terms of network costs, is by sending efficient economic signals to network users that encourage them to make efficient use of the network (Batlle, 2011).

Several tariff design objectives can be derived based on the principle of economic efficiency (Morell Dameto et al., 2020):

- Cost-reflectivity: network users pay the full costs of the electricity service, recognizing that electricity costs may vary by time, location, and supplied quality (Pollitt, 2018).

Additional objectives related to the economic efficiency and in some way elements of cost-reflectivity are:

o Cost-additivity: tariffs are formed aggregating different cost categories or items to reflect the total system costs. 
o Symmetry: costs that depend on consumption and injection of energy or power are charged/rewarded equally at the same location and time.

o Robustness against customer aggregation: costs that do not change depending on whether consumption is aggregated or individualized per customer should not be charged differently to the aggregated customers than to the individual customers.

- Predictability: in the short term, customers should be able to precisely estimate ex-ante the level of their network charges. In the long term, predictability of tariffs and their methods of calculation provides regulatory certainty to network users.

- Technology neutral: tariffs should be unbiased concerning the particular use case of different network users or the technology used to withdraw or inject energy into the grid (Pérez-Arriaga, 2013).

- Minimization of cross-subsidies: one consumer's actions should not negatively impact other customers' charges.

Efficient economic signals should try to capture and reflect the marginal or incremental utilization cost of electricity services. Such signals serve as the key indicator to coordinate planning and operational decisions made by market participants, including customers, to achieve efficient outcomes.

The treatment of any costs, which are not affected by changes in electricity consumption or production, is equally important. The methodology used to recover these so-called residual costs must be carefully designed, avoiding any distortion of the economic efficiency aimed by cost-reflective charges (Pérez-Arriaga, 2016), and at the same time, allocating those costs following equity principles, introduced in the next section.

\subsection{EQUITY}

The term "equity" has many different definitions. For example, some may consider as equitable those tariffs which ensure that all customers within a service territory pay the same charge per-kilowatt-hour $(\mathrm{kWh})$ regardless of when or where they consume. Many scholars have noted that such a tariff design benefits some customers at the expense of others, i.e. some customers pay less than the costs they create, while others pay more. As a consequence, the application of the equity principle may come at a significant societal cost. Making informed tariff design decisions requires a profound understanding of these trade-offs (Burger et al., 2019).

Equity considerations in relation to electricity tariff design can be split into specific sub-principles, namely allocative equity, distributional equity and transitional equity.

- Allocative equity: Identical network usage should be charged equally. Identical network usage refers to comparable location and consumption patterns, regardless of payer nature, energy final usage, or appliances behind the meter (Burger et al., 2019; Pérez-Arriaga, 2013).

Although allocative equity is a consideration of the equity principle, its implications are completely aligned with the aforementioned economic efficiency principle. For example, one of the main implications of allocative equity is that marginal consumption/production should be charged/paid according to marginal costs/values it creates (Burger et al., 2019). This can be considered as cost-reflectivity and symmetry as previously explained, and therefore would lead to a more efficient system. Another important implication is that residual costs should be allocated according to customer characteristics that are not impacted by their consumption or production decisions in the short term. This definition of equity provides regulators with a certain degree of freedom to group customers in different categories. For instance, regulators could use wealth or other customer characteristics to classify them and then allocate the system's residual cost among those different customer categories. Section 5.2 dives into this issue in more detail.

- Distributional equity: Charges should be proportional to the economic capability of each user. This is in conflict with economic efficiency principles, e.g. cost reflectivity. It is possible that efficient tariffs could have undesirable distributional outcomes for some vulnerable customers. When designing residual costs allocation, regulators often use tariffs as a means to achieve distributional outcomes (Burger et al., 2019; Strielkowski et al., 2017).

- Transitional equity: A transition from an old tariff scheme to a new one should be gradually implemented. The aim of a tariff change is to improve net welfare and in the long-term reduce the cost for network users. However, these changes could also entail that certain customers or customer groups have to pay more. Regulators and policy makers should address these concerns, since customers cannot reasonably account for future unexpected tariff changes in their investment decisions. One of the key methods to alleviate transitional equity challenges is by implementing changes gradually.

While the main objective of economic efficiency is to send the right price signals to achieve the optimal development of the electricity system, the main objective of the equity principle is to allocate mainly residual costs, taking into account allocative, distributional and transitional effects among different customer categories and without distorting efficient signals.

\section{REVISITING TARIFFS UNDER DECENTRALIZATION, DIGITALIZATION AND DECARBONIZATION}

The 3-D's transformation imposes the need for revisiting how the principles for tariff design, explained in section 3 , are addressed by traditional tariffs, and how tariffs should otherwise be adapted to the new situation.

\subsection{DIGITALIZATION AND COST- REFLECTIVE GRANULAR TARIFFS}

Digitalization offers new opportunities for efficient customer responses, and the tariff design should take this into account (Pérez-Arriaga, 2016). Digitalization does not only imply the large-scale deployment of metering systems, but also encompasses home and building automation. In addition, digitalization creates new business models for aggregators that cluster the response of thousands of consumers and, as such, could provide system services, i.e. through flexibility markets. 
Consequently, this would allow small consumers to provide flexibility services to transmission and distribution system operators (Glachant and Rossetto, 2018; Prettico et al., 2019).

Digital data collection, computing power, and data transfer have improved tremendously in recent years. This creates an opportunity to define more cost-reflective granular tariffs with higher locational and temporal discrimination. The resulting tariff structure would be more complex and subdivided into multiple parts. In retail markets, nevertheless, retailers are responsible for recovering regulated tariffs together with electricity market prices and retail margins via the final customer bills. Retailers would find value in offering residential or small consumers the option to hedge against price volatility by creating simplified bills that can be easily understood, particularly for consumers with little capability to become active customers. In addition, retailers and aggregators could opt for offering more sophisticated price and tariff structures to those customers that are reactive to flexibility incentives.

In addition, digitalization has the potential to increase the traceability and transparency of information. This allows detailed signalling of where the different charges come from, given that transparent methodologies for cost allocation are in place. For instance, by using apps that display market prices and signal system operation conditions, active customers, directly or through aggregators, could respond by modifying their consumption patterns creating higher system efficiency.

A deeper knowledge of customer consumption patterns - provided by smart meter data - and their relationship with customer metrics about wealth or income, would enable better customer segmentation and granularity, allowing the design of more efficient and equitable tariffs (Morell Dameto et al., 2020).

\subsection{DECARBONIZATION POLICIES AND FAIR COST ALLOCATION}

Some studies foresee that ambitious decarbonization policies imposing high penetration targets for renewable generation in the electricity system will need some sort of support mechanism, additional to the market price, to ensure investment recovery for RES investors (Gerres et al., 2019b). Depending on the market designs, the extra cost of RES support mechanisms can be allocated to final customers as a regulated cost to be recovered through the tariff.

Increasing the burden of supporting renewables or other environmental policies via the tariff, especially when flat volumetric energy and/ or net-metering charges are applied to recover those costs, could have consequences on distributional effects between passive and active customers (Mastropietro, 2019).

The decarbonization of the energy system also requires the electrification of other end energy uses, like heating and cooling and transportation through electric vehicles (Barrera, 2019). Electricity tariffs may also support, or at least should not be an obstacle to these objectives. Tariff design, for example, can provide for a reduction of energy and capacity charges at night, always preserving the main principles of economic efficiency and equity.

Given ambitious RES targets and much more distributed RES generation, a higher locational granularity applied to network charges is needed to provide cost-reflectivity and efficiency for the use of existing network infrastructure.

\subsection{DECENTRALIZATION AND CUSTOMER RESPONSE BEHIND THE METER}

Electricity tariff design is affected by those environmental and energy policies that may involve additional costs which would need to be allocated, among others, to electricity customers. As of today, renewable subsidies in many EU countries account for a major share of the policy costs reflected in the electricity bill, as can be observed in Figure 1 (ACER, 2020).

Net-metering tariffs - those accounting for the net exchanged energy with the grid, i.e. subtracting self-generation from consumption within predetermined billing periods - incentivize customers to install distributed renewable generation behind the meter, mainly solar photovoltaics (PVs). As a consequence, active customers - customers installing PVs - partially avoid paying regulated costs, while the rest of customers cross-subsidize them by bearing these costs (Strielkowski et al., 2017).

The same effect, but to a lesser extent, is observed when flat volumetric energy charges are applied to recover network costs. Those charges over-incentivize customers to install self-generation to reduce their net energy consumption obtained from the grid. This effect reduces the total network payments by active customers, yet total network system costs are not equally reduced. Thus, regulators would have to increase those energy charges to fully recover network costs for the next tariff settlement period. The users who did not install self-generation would face higher rates for the same electricity consumption, so they would be further encouraged to invest in self-generation. According to several authors, the redesign of tariff structures is needed to counteract these effects (Brown and Sappington, 2018; Pérez-Arriaga, 2016; Siano, 2014).

This side effect caused by providing hidden incentives through tariff design to decentralized technology solutions might complicate system cost recovery. As a consequence, tariffs would have to rise, thereby negatively affecting the principles of stability and predictability (Nijhuis et al., 2017).

Furthermore, a level playing field should be built for both centralized and decentralized energy resources. In other words, tariffs should send efficient economic signals to invest in the most beneficial technology for the system, regardless of size or use (Barrera, 2019).

Research projects and literature refer to active customers - with PV, demand response, batteries, and/or EV - as flexibility providers to the grid, improving grid efficiency (Abdelmotteleb et al., 2018; Bergaentzlé et al., 2019; Pérez-Arriaga, 2016). At the same time, distributed generation could improve system reliability since system failures can be mitigated with local resources. As a consequence, the procurement of flexibility services by network operators is becoming more and more relevant, for instance, with the creation of local flexibility markets (Abdelmotteleb et al., 2018). In this context, the tariff design should not become an obstacle for active customers to provide these flexibility services, for instance, ensuring that active customers with energy storage facilities are not subject to double charging, including network charges, when providing flexibility services to network operators (Directive (EU) 2019/944, 2019). 


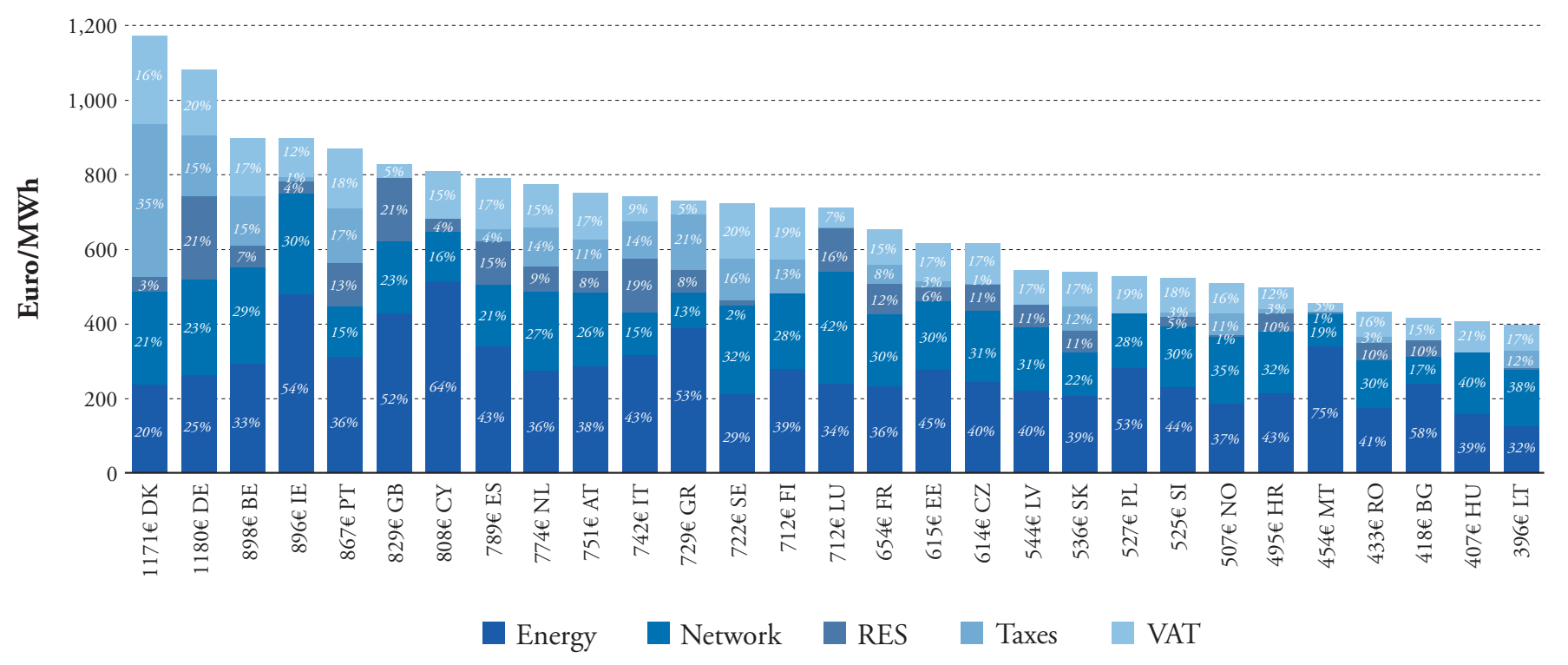

FIGURE 1. COMPOSITION OF ELECTRICITY BILL FOR HOUSEHOLDS IN CAPITAL CITIES. SOURCE: ACER (2020).

An extreme case of system decentralization occurs when a customer decides to completely disconnect from the grid and self-provides energy needs through alternative sources. This effect is known as grid defection. In this case, the electricity system or the rest of customers should not bear the part of the residual costs that still remain in the system and were covered by the defected customer. This issue opens a discussion about the potential application of exit fees or alternative tariff designs to recover these residual costs when defections occur (Burger et al., 2019; Haapaniemi et al., 2019).

\section{NETWORK COSTS AND CHARGES}

As has been described, the 3-D's transformation poses new challenges for electricity tariffs and uncovered issues related to efficiency and equity for tariff design. In this section, the allocation of network costs is re-evaluated by following the aforementioned principles and accounting for the effect of the 3-D's.

The electricity network is a capital-intensive business. Network costs mainly consist of capital expenditures (CAPEX) associated with network infrastructure investment with long depreciation periods, and operation and maintenance costs related to this infrastructure (OPEX). Additionally, energy losses within the network and the low quality of service costs are also considered.

The cost minimization objective imposed by regulators to the monopolistic network operator is mainly targeting the minimization of longterm network expansion costs, while specific incentives are included for energy loss reduction and improvement of quality of service indicators. From the point of view of network tariff design, some authors conclude that the main signal to be transmitted to network users should aim at minimizing the long-term incremental network costs. In underutilized systems, this signal is not enough to recover the required network revenues. In this case, the remaining part to full cost recovery is defined as network residual costs (Pérez-Arriaga, 2016). Long-term incremental costs are associated with the network reinforcements needed in the future, and additional investments if the network usage continues to grow during the maximum demand periods (Bonbright, 1961). Therefore, as will be discussed in section 5.1, long-term network costs should be recovered through peak-coincident charges. Residual costs, as commented, are the proportion of the total network costs that are not recovered through the previously defined peak-coincident charges. It is important to note that long-term incremental costs and residual costs are dependent on both the actual grid and the foreseen grid usage.

Some countries, like the UK, have already developed a network cost allocation methodology, which differentiates between long-term incremental network costs and residual costs (Ofgem, 2019a). The rest of the analysed countries do not make this distinction, and they apply the same allocation methodology to the sum of all network costs. It needs to be highlighted, though, that in some countries, customers (usually LV consumers) face a single charge for the generation, network, policy, and commercialization costs, as explained in section 1.1. The latter is neither efficient nor equitable.

In section 5.1, long-term incremental network costs are defined and an efficient methodology for the allocation of these costs is proposed. Section 5.2 deals with the issues related to the residual costs definition and the principles that should guide their allocation among network users. Section 5.3 deals with the compatibility between peak-coincident charges and connection charges. Finally, section 5.4 provides useful insights on the complementarity of flexibility market mechanisms and long-term incremental network charges. 


\subsection{LONG-TERM INCREMENTAL NETWORK COSTS AND CHARGES}

Network operators should plan and develop network infrastructures which cope with expected demand growth and future network connections at minimum cost, while maintaining quality of service levels. According to cost-reflectivity principles, network users should receive the right economic signals to optimize these long-term network expansion costs.

First, it is necessary to calculate the long-term incremental network costs, and second, determine how these costs should be allocated to network users. This could be done, for example, through charges with different time-blocks (flat, time-blocks of several hours or hourly), through different charging variables (energy or capacity), or through charges with or without spatial differentiation. Long term incremental costs are discussed in section 5.1.1, and section 5.1.2 addresses the question of allocation.

\subsubsection{LONG-TERM INCREMENTAL COSTS CALCULATION AND DRIVERS}

Long-term costs are those future costs that DSOs and TSOs will face to maintain system integrity and quality of service given an increasing electricity demand. Therefore, long-term costs correspond to the expected costs of the network expansion planning. Investments in network assets are discrete and irreversible, and they are performed every few years note that the lifespan of these assets is 40 years and beyond.

At the same time, incremental demand changes also differ over time. Therefore, in order to compute the long-term incremental costs, it is necessary to bring future costs caused by incremental demands to present value, to signal current customers their potential impact on the future grid.

From a theoretical point of view, the main trigger for future network investment is the maximum peak usage of each network element, i.e. the maximum energy flow through the network element, which is due to both the generation and demand contributing to that maximum flow, as stated in (Abdelmotteleb et al., 2018). Although this is a feasible approach, it would be very costly to monitor each one of the network elements, and therefore this approach would not be practical. A much less costly alternative would be to divide long-term network costs according to regions, zones, or clusters of nodes. Thus, regulators should evaluate pros and cons of applying long-term network costs with a higher or lower locational granularity, while taking into account that the theoretical main cost driver is the maximum network flow at each network component.

\subsubsection{LONG-TERM INCREMENTAL COSTS ALLOCATION}

Once long-term network costs have been calculated, it is necessary to efficiently signal customers to guide them towards an optimal usage of the electricity network. First, we discuss whether producers should also face long-term incremental costs. According to the economic efficiency principle and the cost-reflectivity and symmetry criteria, when allo- cating long-term incremental network costs, producers and consumers should be treated equally. Furthermore, the existence of active customers emphasizes the need for this symmetry, as they consume from or inject power into the grid during different time periods.

Since long-term incremental costs are driven by the maximum peak usage of the network, those customers contributing to maximum peak usage would be responsible for the required future network investments in each particular network component or network zone. Thus, charges designed to signal long-term costs should be forward-looking peak-coincident network charges, i.e. higher charges in those periods with expected higher network usage.

Under a purely theoretical approach with perfect knowledge about the future network characteristics, it would be possible to know the peak hours of each network element. This means that customers could be charged according to their contribution to the peak hours in each of the network elements. However, in practice, and when smart meters are deployed, a common methodology is to select those hours on which the network is expected to be more used, defining those time blocks as peak hours and the rest as off-peak hours.

Ideally, the more temporally differentiated a tariff signal is, the higher the level of efficiency that can be achieved. Additionally, a shorter price setting period may provide more dynamic responses from customers, as explained in section 2. However, implementation costs of granular and dynamic tariffs - not only due to the technical development of smart meters and markets, but also customer awareness and engagement must be compared to the potential benefits in terms of long-term system costs and efficiency.

Once system-peak periods have been identified, regulators should decide whether peak charges should be signalled through energy or capacity charges. If a high time granularity is applied by establishing a sufficient number of time blocks, energy charges could provide more efficient and equitable outcomes than capacity charges. This is due to the fact that customers who intensively use the grid during peak timeblocks should be charged more than customers who have a punctual demand peak during those peak-time blocks. According to this, if capacity charges are applied, a customer who experiences a significant high consumption due to a largely unavoidable situation at the beginning of a peak time-block, does not receive any incentive to efficiently manage consumption for the rest of the hours within that peak timeblock. This randomness of sporadic short high consumption or injection situations can be entirely avoided through energy charges at the peak-coincident time-blocks. Thus, energy pricing provides superior incentives to optimize usage at all relevant times within the peak time blocks (LeBel et al., 2020).

In essence, the best option for signalling long-term incremental network costs would be to implement peak-coincident energy charges that measure the contribution of network users to the peak network flows in the time-blocks of maximum utilization. This economic signal would incentivize user responses to reduce network peak flows and delay future grid investments.

Finally, there is a discussion about the efficiency and equity issues of applying a geographically differentiated network charge. On the one hand, the principle of economic efficiency would lead us to design peak-coincident network charges with a high level of locational granularity to incentivize efficient network user responses depending on 
the particular network components that are expected to be congested. On the other hand, equity concerns would advocate for allocating the same charges to a large proportion of customers under the same categories regardless of their location (Pérez-Arriaga, 2016; Schittekatte and Meeus, 2018).

\subsection{RESIDUAL NETWORK COSTS AND CHARGES}

After subtracting the part corresponding to the long-term incremental network costs, residual network costs are the remaining part of total network costs to be collected. The amount of residual network cost is independent of any customer response and therefore not driven by them.

For recovering residual network costs, it is recommended to allocate them in a way that does not impact other efficient price signals, such as peak-coincident charges or energy market prices. Network users should not be able to avoid this payment by modifying their consumption/ injection patterns. In addition, these charges could allow equity issues to be addressed, based on how charges are applied to the different customer categories. The United Kingdom (UK) regulator is moving in this direction. In the UK, there is a proposal to recover residual network costs through a fixed charge for domestic customers, depending on the aggregated net consumption of the customer category and equal charges for customers under the same category (Ofgem, 2019b).

Another discussion related to the allocation of residual network costs is whether or not producers should pay these costs. Assuming that there is not cost-reflectivity and producers compete in the electricity market, they would simply internalize these costs in their energy sales, with potential distortion of competition and being finally paid by consumers. Therefore, it is recommended that residual charges should be solely allocated to consumers.

Residual network costs share the same allocation challenges as policy costs, because both costs have no driver. Therefore, this issue will be addressed in section 6 .

\subsection{COMPATIBILITY BETWEEN PEAK-COINCIDENT AND CONNECTION CHARGES}

Peak-coincident and residual network charges are use-of-system charges. They are charged periodically, monthly or bimonthly with the aim of recovering network costs and collecting allowed revenues for network operators. In addition to those use-of-system charges, connection charges are used by network operators when a new user connection is required in the system. A connection charge is a one-off payment that new customers or those requesting a higher network connection capacity must face due to needed network reinforcements. In general, three types of connection charges can be distinguished: super-shallow, shallow and deep connection charges. The degree to which connection charges fully reflect the incremental cost of providing a user with a new or upgraded connection to the network depends on the type of connection charge. In the case of super-shallow connection agreements, basically no costs are charged for the connection. Shallow charges only consider the new extension from the existing grid to the connection point of the new user, while deep connection charges additionally include all the network reinforcements in the existing network required to accommodate the power flows from the new connection (Schittekatte and Meeus, 2018).

Introducing forward-looking peak-coincident network charges, as a use-of-system charge, requires consideration of the potential overlaps with the traditional connection charging concept, because both types of charges attempt to reflect the network costs that individual network users could cause.

Applying deep connection charges and forward-looking charges would be conflicting, because the same network costs would be signalled twice, through both mechanisms. On the other hand, super-shallow connection agreements would be fully compatible with forward-looking peak-coincident charges.

\subsection{LOCAL FLEXIBILITY MECHANISMS}

Traditionally, distribution system operators do not consider flexibility services provided by third parties - for example, producers, consumers, or active customers - when planning new network reinforcements to reduce network incremental costs or, in the short-term, when they have to deal with potential congestions or voltage problems. In the future, these services would be procured through so-called local flexibility mechanisms, such as long-term auctions, short-term markets, bilateral contracts, and regulated payments.

In some way, those local flexibility mechanisms and cost-reflective peak-coincident charges have the same objective, reducing future network costs, and complement each other.

As we have commented, network tariffs are usually designed for large systems. Local flexibility mechanisms, though, are designed ad-hoc for dealing with congestion problems or system reinforcements that mainly affect specific network components located within those larger areas. In this way, both mechanisms are complementary in terms of geographical scope.

Likewise, flexibility mechanisms can be implemented to introduce geographical discrimination in countries where legislation prevents doing this via network tariffs. Local flexibility markets can be another option to deal with potential grid congestion problems that are difficult to manage under cost-reflective dynamic tariffs. Here, the suitability of different options depends on how extensive the required customer reaction should be. For instance, system-wide reactions, caused for example by a heat wave, are better achieved by broadcasting high network tariffs for the following day during peak-use hours, while local resources to solve specific network congestion, occurring at different times and locations, can be better mobilized under local flexibility markets (Gómez San Román et al., 2020).

A key difference between dynamic tariffs and local flexibility mechanisms is that the former rely on the uncertain reaction of potentially responsive network users, whereas the latter force flexibility providers to commit to providing the service in response to the grid operator's command. In fact, in some cases, this response may be automatic. Hence, local flexibility markets enable network operators to rely on flexibility for actively managing the network in daily grid operations, 
and to avoid grid reinforcements when planning the expansion of the grid (Gómez San Román et al., 2020).

We can conclude that local flexibility mechanisms and forward-looking peak-coincident charges are compatible and complementary. While flexibility markets aim to mitigate critical congestion or avoid network reinforcements in specific areas or components of the system, network tariffs search for a wider system response to achieve an optimal grid development. Furthermore, the response of network users with ad-hoc flexibility mechanisms is more certain than with network tariffs.

\section{POLICY COSTS AND TAXES}

Policy costs include renewable subsidies and other costs that are not related to the grid usage, mainly derived from energy, environmental or social policies. Most of these policy costs do not have a clear driver related to electricity consumption or injection in the system, and can therefore actually be considered as residual costs. Among efficiency or equity principles for their allocation, in general, equity criteria are considered. In particular, it is recommended that their allocation should not distort the efficient cost-reflective energy prices and network charges previously discussed. Some academics take a more radical stance, calling for an exclusion of some policy costs from the electricity bill, and recovery of these costs through the national public budget (Pérez-Arriaga, 2016).

\subsection{WHICH COSTS SHOULD BE INCLUDED IN ELECTRICITY TARIFFS?}

There are several negative consequences of including residual network and policy costs that are not directly affected by changes in electricity consumption in electricity tariffs. There is a very clear risk of efficiency loss, in the case that they distort cost-reflective prices and network charges. On the other hand, meeting decarbonization targets, as it has been explained, is related to electrification of final energy uses currently supplied by non-renewable fuels. Increasing electricity prices with policy costs would discourage the use of electricity with respect to competing alternative fuels. Finally, another potential consequence of including policy and residual network costs in the tariff is grid defection. In most cases where the network is already in place, grid defection results in a reduction of social welfare.

Every cost item which can be considered a policy cost should be subject to scrutiny. In many jurisdictions, subsidies to promote low-carbon technologies - renewable generation, in particular - are a significant part of the policy costs in the electricity tariff. Certainly, electricity production is an important contributor to greenhouse gas emissions, but other sectors of the economy contribute as well. Since the electricity system appears to be easier and faster to decarbonize than other sectors, support policies with economic incentives were concentrated on renewable generation technologies, mainly solar and wind. Therefore, it seems justifiable to share the burden of electricity decarbonization i.e., the corresponding policy costs - among customers of other energy sectors as well, and, in this way, decrease the costs on the electricity bill (Batlle, 2011). For example, in the United States a substantial fraction of the cost of renewable support schemes is born by federal, state, or local taxes (Pérez-Arriaga, 2016).
A more radical proposition is to question whether the residual component of electricity network costs, both transmission and distribution, could be allocated to taxpayers instead of electricity customers. This topic would become more relevant if the cost reductions for distributed generation and storage units turn grid defection into a widespread, economically attractive alternative within the power system.

\subsection{RESIDUAL COSTS ALLOCATION}

Recovering residual network and most policy costs with a flat energy rate per $\mathrm{kWh}$ consumed, regardless of the time or the location of this consumption, can result in a significant distortion. This approach invites network users to net out their demand for electricity by installing system-wide inefficient self-generation behind the meter. By cancelling electricity demand with embedded generation, those customers would avoid paying residual costs, which would have to be reallocated to other customers. Moreover, since the rest of customers face higher flat energy rates, they are more incentivized to adopt self-generation, thus exacerbating the utility 'death spiral' effect (Simshauser, 2016).

A different approach would be to recover policy costs via a fixed charge which would be determined annually by the regulator for each customer and then charged, for instance, in equal monthly instalments. In principle, this annual charge would not distort short-term and long-term efficiency signals. However, there are obvious equity implications: Should all network users pay the same charge, irrespective of their energy consumption or their peak or contracted power? Residential customers that consume more energy are likely to be wealthier than customers that consume less energy. An equal fixed charge for all customers would disproportionately affect low-income customers, which would be socially unacceptable. This discussion can be extended to commercial or industrial customers. Although an annual charge not directly linked to electricity consumption is an efficient instrument, further considerations on how to allocate this sum to customers is required.

As a qualitative assessment, we can compare how three different types of charges, mainly for residential customers, perform considering the aforementioned equity principles.

\section{Fixed charge based on the income level or the real estate tax}

The allocation of residual costs according to the income level of residential customers allows progressive charges with respect to consumers' income. The real estate tax could also be a proxy for the income level of the owner. This fixed progressive charge would meet equity criteria, as well as being independent of the level of consumption.

This fixed charge would be independent from the consumption or contracted power of the consumer, or whether the consumer decides to install self-generation or storage units. The collected amount would also not change if several consumers are aggregated as a cluster with a single connection point to the system, forming, for instance, a citizen energy community. Finally, this charge would easily be applicable to new consumers requesting connection to the grid.

On the other hand, the practical implementation of this type of charge would be complex due to access to the information, which is not relevant for the operation of the electricity system, but required for its 
implementation. Both income data and real estate taxes are traditionally not available to utilities. In addition, substantial regulatory changes for their implementation would be needed with respect to current practices.

\section{Contracted or installed capacity charge}

A less radical approach compared to the current situation is to use the contracted capacity or the installed capacity, i.e. the maximum allowed capacity for a consumer installation based on technical standards, to allocate residual costs. This approach is currently used for the allocation of other regulated costs in some jurisdictions. However, any charge related to the size of the customer connection can introduce barriers to electrification. To avoid this, the application of this charge could be exempted in off-peak periods. The charge would be fixed for the whole year, proportional to the maximum capacity contracted for peak time-blocks, as is expected to be applied in Spain in 2021, or in line with the proposal of the Italian energy regulator shown in section 2.2. In this way, no extra costs would be added to consumption or generation during offpeak hours, and therefore no barriers would be created, for instance, to electric vehicle recharging during periods of low network utilization.

Contracted capacity and installed capacity can be modified by the customer, but only to a certain extent, because a customer must contract or install capacity which corresponds to his maximum consumption. In addition, these charges are basically not avoidable for customers with photovoltaic self-generation installations, since they are not controllable, and thereby not able to reduce their contracted capacity.

This proposal, however, is not robust against cross-subsidies that could arise, for example due to the installation of storage systems which would allow contracted or installed capacity to be reduced, or due to supply point aggregation which would enable all consumers to reduce contracted or installed capacity, since the aggregated maximum capacity would be less than the sum of the individual maximum capacities. Contracted or installed capacity, as charging variables, are directly applicable to new consumers requesting connection to the grid. Finally, this allocation method is also easily applicable to commercial or industrial consumers.

TABLE 3. QUALITATIVE COMPARISON OF RESIDUAL COST ALLOCATION METHODS

\begin{tabular}{|c|c|c|c|}
\hline Criteria & $\begin{array}{l}\text { Fixed charge } \\
\text { based on } \\
\text { income level }\end{array}$ & $\begin{array}{l}\text { Contracted or } \\
\text { installed capacity } \\
\text { charge }\end{array}$ & $\begin{array}{l}\text { Fixed charge } \\
\text { based on } \\
\text { historical } \\
\text { consumption }\end{array}$ \\
\hline \multicolumn{4}{|c|}{ Non-modifiable by consumer's actions } \\
\hline \multicolumn{4}{|l|}{ Easy transition } \\
\hline \multicolumn{4}{|l|}{ Robust against self-generation } \\
\hline \multicolumn{4}{|l|}{ Robust against storage } \\
\hline \multicolumn{4}{|l|}{ Distributional equity } \\
\hline \multicolumn{4}{|l|}{ Robust against customer aggregation } \\
\hline Easy applicable to new customers & & & \\
\hline
\end{tabular}

Note. Summarizes the different alternatives discussed to design residual charges with associated implications. 


\section{Fixed charge based on historical consumption}

The central idea of this last alternative is to seek the "historical" responsibility of each customer for the stranded residual costs. For example, historical energy consumption could be considered a reasonable indicator of the costs associated with past policy costs, i.e. historical costs of support mechanisms for renewable energy. The calculation by which the fixed charge to each consumer is determined takes its annual historical consumption as a reference.

The relationship between historical consumption and income level is not so clear. It is presumed that consumers with higher incomes have more household appliances and therefore higher consumption. But, low income consumers have less efficient appliances or poorly thermally insulated homes. By defining a fixed charge on historical consumption that would not be updated, consumers could not change their payments by changing their actual consumption patterns.

The transition from current tariff designs to this alternative would not be difficult because utilities already know the required data. The associated fixed charges could not be avoidable by customers installing self-generation and storage technologies. Despite this, it presents some problems of applicability to new consumer connections where historical consumption data would not be available. To resolve this, default charges could be set taking as a reference consumers with similar characteristics (Batlle et al., 2020).

As we mentioned, there is no one-size-fits-all solution, and the application of one method or another will be up to national regulators, based on the applicable laws, data accessibility, network technical development, and customer engagement.

\section{EFFECT OF ELECTRICITY TARIFF DESIGN ON DEPLOYMENT OF NEW TECHNOLOGIES}

Electricity tariffs, along with smart meters and new energy technology deployment, are critical in order to make the energy transition more efficient and environmentally sustainable. Long-term incremental network charges are responsible for the efficient allocation of network costs. Nevertheless, residual costs should not distort economic signals provided by long-term incremental charges or energy prices. An impact assessment of described tariff designs is required to find out their effects on the customer adoption of these new technologies and implications for system efficiency.

In an ideal world, electricity tariffs should provide economic signals to customers to invest in the most economically efficient technology from a system perspective, while maintaining a level playing field between technology options. It is necessary to note that depending on the applied tariff structure, the most economically efficient actions taken by customers for their own benefit would not always improve efficiency from a system perspective. This analysis is therefore based on a comparison between system and individual benefits for various technology alternatives for customers under three different tariff structures: a peak-coincident energy charge plus a fixed charge according to what was presented in sections 5 and 6 , a maximum individual demand or contracted capacity charge $(€ / \mathrm{kW})$ and, finally an energy charge $(€ / \mathrm{kWh})$.
Under the new paradigm, customers can choose between adopting several technologies or actions to respond to electricity prices and tariffs. These actions can be simplified into three groups: i) to invest in non-controllable and intermittent self-generation, such as solar PV panels; ii) to invest in controllable flexible loads, such as storage, electric vehicles or heat pumps; and iii) to engage with other customers, forming a cluster or aggregation with a single connection point to the grid. Electricity tariff design is a key element that affects the future of the electricity system, acting as a driver for customers' investment decisions.

\subsection{NON-CONTROLLABLE AND INTERMITTENT RENEWABLE GENERATIONS}

One of the main characteristics of renewable self-generation technologies is their uncontrollability and their intermittency. These aspects make it difficult to align generation with peak demand, either local or upstream, which is the main trigger for network investments. RES generation alone would contribute to neither delaying network reinforcements nor lowering future network costs. Therefore, network tariffs should not over incentivize non-controllable and intermittent RES generation. In those cases when RES self-generation contributes to lowering peak demand, their installation would be reasonably rewarded if peak-coincident charges are applied.

In the case of applying maximum individual demand or contracted capacity charges, tariffs would fail to account for situations when RES self-generation is aligned with the network's peak demand. In this case, affected customers installing RES self-generation would not be rewarded, since the estimated system benefit would be greater than the individual benefit. On the other hand, as it has been explained in section 6.2, flat energy charges would increase the individual benefits for those customers adopting RES self-generation, further incentivizing its adoption, and eventually jeopardizing the total network costs recovery. Although this problem could be mitigated through time-block differentiated energy charges, it does not address the issue that an important part of the network costs are residual costs and not related to energy consumption. Consequently, recovering these residual costs through energy charges will lead to losses in system economic efficiency.

\subsection{CONTROLLABLE FLEXIBLE LOADS}

Controllable flexible loads are an efficient alternative for customers to respond to electricity prices and charges. They include storage, electric vehicle, and heat pump technologies, and also other types of loads that can be curtailed or shifted from high to low price hours. With the development of smart meters, and increasingly dynamic tariffs, customers would be able to benefit from flexible load control. From this perspective, peak-coincident network charges and fixed residual charges provide optimal incentives to invest in efficient amounts of controllable loads, taking into account the benefits from a system perspective, and at the same time ensuring total cost recovery through residual charges.

If maximum individual demand or contracted capacity charges were applied, controllable loads would tend to flatten the customer consumption profile by minimizing the individual maximum demand or contracted capacity. Under this tariff design, individual benefits could 
be higher than system benefits. Network peak events would not be precisely identified, and flattening individual load profiles could not be justified at times when the network is not stressed.

On the other hand, flat energy charges would not create any incentive to efficiently manage consumption by controllable flexible loads. However, if time-block differentiation is applied, controllable loads would shift the maximum available amount of energy from high price to low price time-blocks.

In both cases, energy and capacity charges can be temporally differentiated with the aim of signalling the system peak. However, there are two main concerns to be considered: i) how time blocks are defined to correctly identify peak periods, and ii) how much of the total network and policy costs are allocated through ToU capacity or ToU energy charges. In the case of not separating residual costs from the allocation of the total costs, incentives for a customer response may be higher than optimal, eventually causing inefficiencies.

It is important to take into account that in the case of controllable loads, customers' actions are dependent on the signals received from both the electricity market prices and the network tariffs, which can be aligned, or not, in time and locations.

\subsection{CUSTOMER AGGREGATION IN A SINGLE CONNECTION POINTS}

The aggregation of customers in a single connection point is clearly beneficial for customers who face contracted capacity charges or individual maximum demand charges. By this tariff design, through aggre- gation, customers are able to avoid a large portion of network charges. On the other hand, in the case of energy charges, there are no apparent benefits from customer aggregation. The same amount would be recovered from the aggregated customer charge as from the sum of individual charges. Therefore, while energy charges are robust against customer aggregation, capacity charges fail to fulfil this objective.

Peak-coincident charges and fixed charges would be robust against customer aggregation depending on the residual cost allocation method, as has been explained in section 6.2 and Table 3 .

\subsection{SUMMARY}

Table 4 summarizes the effects analysed in this section. As has been previously commented, incentives to customer response must also provide benefits to the system and the rest of customers. One of the main objectives of electricity tariff design must be to provide adequate incentives to foster optimal customer response, although not all tariff structures achieve this objective, as previously discussed. Energy charges provide over incentives to non-controllable and intermittent RES self-generation, while underestimating network services that could be provided by controllable flexible loads. Contracted capacity charges provide over incentives to controllable flexible loads at the same time that self-generation is not adequately remunerated, and customers are incentivized to inefficiently aggregate themselves under one single connection point. If accurately designed, the mix of peak-coincident and fixed charges could be able to send the right economic signals for encouraging active customer responses, while preserving global system efficiency and benefitting the rest of customers.

\section{TABLE 4. EFFECT OF ELECTRICITY NETWORK TARIFFS ON NEW TECHNOLOGY DEPLOYMENT AND CUSTOMER AGGREGATION}

\begin{tabular}{|c|c|c|c|}
\hline & $\begin{array}{c}\text { Peak-coincident } \\
\text { charges }(€ / \mathbf{k W h}) \\
+ \text { Fixed charges } \\
(€ / \text { customer })\end{array}$ & $\begin{array}{c}\text { Maximum individual } \\
\text { demand or } \\
\text { contracted capacity } \\
\text { charges }(€ / \mathbf{k W})\end{array}$ & $\begin{array}{c}\text { Energy charges } \\
(€ / \mathbf{k} \mathbf{W})\end{array}$ \\
\hline $\begin{array}{c}\text { Non controllable } \\
\text { and intermittent RES } \\
\text { self-generation }\end{array}$ & $\mathrm{SB}=\mathrm{IB}$ & $\mathrm{SB}>\mathrm{IB}$ & $\mathrm{SB}<\mathrm{IB}$ \\
\hline $\begin{array}{c}\text { Controllable flexible } \\
\text { loads (Storage, EV, } \\
\text { Heat Pumps) }\end{array}$ & $\mathrm{SB}=\mathrm{IB}$ & $\mathrm{SB}<\mathrm{IB}$ & $\mathrm{SB}>\mathrm{IB}$ \\
\hline $\begin{array}{c}\text { Customer } \\
\text { aggregation with a } \\
\text { single connection } \\
\text { point }\end{array}$ & $\mathrm{SB}=\mathrm{IB}$ & $\mathrm{SB}<\mathrm{IB}$ & $\mathrm{SB}=\mathrm{IB}$ \\
\hline
\end{tabular}

Note. SB refers to the system benefit derived from a customer's response. IB refers to the individual benefit that the respondent customer obtains. $S B>I B$ means that individual benefits of respondent customers are lower than system benefits, $S B=I B$ means that individual benefits are the same as system benefits, and $\mathrm{SB}<\mathrm{IB}$ means that respondent customers receive a higher benefit from their action than they produce in the system. 
Finally, a combination of previous technologies could take the form of a microgrid or an energy community. In these situations, customer's responses would face a combination of the individual effects analysed in this section.

\section{CONCLUSIONS}

All over the world, electricity systems are facing a deep transformation that requires a rethink of electricity tariff structures. The 3-D's drivers, with the deployment of smart meters and other digital technologies, the electrification of transport and buildings, and the large penetration of renewable and DER technologies adopted by active customers, require us to rethink electricity system costs allocation methods.

In Europe, active customers, including small residential consumers, may respond to electricity prices and regulated tariffs with higher temporal and spatial granularity. If those economic signals are cost-reflective, they would maximize the efficiency both for customers and for the whole system.

In this context, European countries are moving toward new tariff designs: from flat to time-block differentiated charges, identifying system peak-hours with higher price periods.

The basic principles on which tariff design should be based, economic efficiency and equity, should be reformulated under this green transition.

Following efficiency criteria, network costs should be segregated into incremental and residual costs. Once costs are disaggregated, charges reflecting those costs must be decomposed into forward looking peak-coincident charges and fixed charges. Peak-coincident charges should be designed to reflect the long-term incremental costs of the network usage and encourage efficient customer responses to reduce future network reinforcements. On the other hand, fixed charges should be designed to recover all the remaining system costs (residual costs), once peak-coincident charges have been levied. Residual fixed charges would not distort efficient customer responses to cost-reflective peak-coincident charges and energy prices.

Additionally, policy costs, including renewable subsidies and other costs mainly derived from energy, environmental or social policies, do not have a clear driver related to electricity consumption or injection in the system. Therefore, they can actually be considered as residual costs.

Peak-coincident network charges with high locational and time granularity would be best for incentivizing efficient price responses, but in many jurisdictions there are legal impediments for the implementation of locational tariffs. A trade-off analysis regarding socialization of costs and tariff granularity must be performed when adopting new tariff designs. On the other hand, following equity principles for the implementation of residual charges, several options are discussed, with fixed charges discriminating users by size, wealth, or other similar proxies being the preferred ones.

Finally, applying traditional tariffs versus best practice designs may have important consequences on the decisions adopted by active customers installing renewable self-generation, controllable loads or aggregating their individual installations in a single connection point to the grid. It is demonstrated that traditional tariffs do not align individual customer benefits with system benefits, creating system inefficiencies and cross-subsidies among customer categories.

It is important to note that no one-size-fits-all tariff model would be the solution for electricity systems in transition. In practice, historical and legal restrictions are predominant when adopting new tariff models. Rather, this chapter should serve as a guide for dealing with the important challenges associated with the energy transition and being aware of the trade-offs involved when designing new tariff structures.

\section{ACKNOWLEDGMENT}

The authors would like to thank Mr Timo Gerres for his comments and suggestions to improve this manuscript.

\section{REFERENCES}

Abdelmotteleb, I., Gómez, T., Ávila, J. P. C., \& Reneses, J. (2018). Designing efficient distribution network charges in the context of active customers. Applied Energy, 210, 815-826. https://doi.org/10.1016/j.apenergy.2017.08.103.

ACER 2020. ACER Market Monitoring Report 2019 - Energy Retail and Consumer Protection Volume. https://www.acer.europa.eu/Official_documents/Acts_of_the_Agency/ Publication/ACER\%20Market\%20Monitoring\%20Report\%202019\%20-\%20Energy\%20Retail\%20and\%20Consumer\%20Protection\%20Volume.pdf (accessed 2 January 2021).

Barrera, F. (2019). Peajes eléctricos. Una barrera para la transición energética. Frontier Economics. https://www.frontier-economics.com/media/3346/frontier-peajes-el\%C3\%A9ctricos-junio-2019.pdf (accessed 1 July 2019).

Batlle, C. (2011). A Method for Allocating Renewable Energy Source Subsidies Among Final Energy Consumers. Energy Policy, 39(5), 2586-2595. https://doi.org/10.1016/j. enpol.2011.02.027.

Batlle, C., Mastropietro, P., \& Rodilla, P. (2020). Redesigning Residual Cost Allocation in Electricity Tariffs: A Proposal to Balance Efficiency, Equity and cost Recovery. Renewable Energy. https://doi.org/10.1016/j.renene.2020.03.152.

Bergaentzlé, C., Jensen, I. G., Skytte, K., \& Olsen, O. J. (2019). Electricity Grid Tariffs As A Tool for Flexible Energy Systems: A Danish Case Study. Energy Policy, 126, 12-21.https:// doi.org/10.1016/j.enpol.2018.11.021.

Bhagwat, P., \& HADUSH, S. Y. (2020). Dynamic Retail Electricity Tariffs: Choices and Barriers. European University Institute, Florence School of Regulation. https://doi. org/10.2870/70613.

Bonbright, J.C. (1961). Principles of Public Utility Rates. http://media.terry.uga.edu/documents/exec_ed/bonbright/principles_of_public_utility_rates.pdf (accessed 3 July 2019).

Brown, D. P., \& Sappington, D. E. (2018). On The Role of Maximum Demand Charges in The Presence of Distributed Generation Resources. Energy Economics, 69, 237-249. https://doi.org/10.1016/j.eneco.2017.11.023

Burger, S. P., Schneider, I., Botterud, A., \& Pérez-Arriaga, I. (2019). Fair, Equitable, and Efficient Tariffs in the Presence of Distributed Energy Resources, in: Sioshansi, F. (Ed.), Consumer, Prosumer, Prosumager. Academic Press, pp. 155-188. https://doi.org/10.1016/ B978-0-12-816835-6.00008-5.

CEER, 2020. Paper on electricity distribution tariffs supporting the energy transition. https://www.ceer.eu/documents/104400/-/-/fd5890e1-894e-0a7a-21d9-fa22b6ec9da0 (accessed 22 January 2021).

CNMC, 2020. Circular 3/2020, de 15 de enero, de la Comisión Nacional de los Mercados y la Competencia, por la que se establece la metodología para el cálculo de los peajes de transporte y distribución de electricidad. https://www.boe.es/boe/dias/2020/01/24/pdfs/ BOE-A-2020-1066.pdf (accessed 1 February 2021). 
CNMC, 2019. Propuesta por la que se establece la metodología para el cálculo de los peajes de transporte y distribución de electricidad. https://www.cnmc.es/sites/default/files/editor contenidos/Energia/Consulta\%20Publica/01\%20Propuesta\%20_CIR_DE_002_19_ peajes_el\%C3\%A9ctricos.pdf (accessed 27 August 2019).

Directive (EU) 2019/944, 2019. Directive (EU) 2019/ 944 of the European Union Parliament and of the council - of 5 June 2019 - on common rules for the internal market for electricity and amending Directive 2012/ 27/ EU. https://eur-lex.europa. eu/legal-content/EN/TXT/PDF/?uri=CELEX:32019L0944\&from=EN (accessed 22 January 2021).

EDP Distribuiçăo, 2020. Tarifas Dinâmicas. Piloto I - Aperfeiçoamento da estrutura tarifária https://tarifasacessoredes.edpdistribuicao.pt/piloto/i (accessed 21 December 2020).

ERSE, 2018. Projetos-piloto para Aperfeiçoamento das Tarifas de Acesso às Redes e Introdução de Tarifas Dinâmicas em Portugal continental https://storage.googleapis.com/ pdf_storage/apresentacaoErse.pdf (accessed 11 December 2020).

EU-Universal project, 2020. D1.1. Characterisation of Current Network Regulation and Market Rules That Will Shape Future Markets. https://euniversal.eu/wp-content/uploads/2020/08/EUniversal_D1_1.pdf (accessed 22 January 2021).

Gerres, T., Ávila, J. P. C., Martínez, F. M., Abbad, M. R., Arín, R. C., \& Miralles, Á. S. (2019). Rethinking the Electricity Market Design: Remuneration Mechanisms to Reach High RES Shares. Results from a Spanish case study. Energy Policy, 129, 1320-1330. https://doi.org/10.1016/j.enpol.2019.03.034.

Gerres, T., Ávila, J. P. C., Martínez, F. M., Abbad, M. R., \& San Román, T. G. (2019). The Role of Nuclear Power Plants in Electricity Systems With High RES Share, in: 2019 IEEE Milan PowerTech (pp. 1-6). IEEE. https://doi.org/10.1109/PTC.2019.8810545.

Glachant, J.-M., Rossetto, N., 2018. The Digital World Knocks at Electricity's Door: Six Building Blocks to Understand Why. http://cadmus.eui.eu//handle/1814/59044 (accessed 29 August 2019).

Gómez San Román, T., Cossent, R., Chaves Ávila, J.P. (2020). Flexible Network Access, Local Flexibility Market Mechanisms, and Cost-reflective Tariffs: Three Regulatory Tools to Foster Decarbonized Electricity Networks. Oxford Energy Forum. http://dx.doi. org/10.2870/934379.

Haapaniemi, J., Haakana, J., Räisänen, O., Lassila, J., \& Partanen, J. (2019). DSO tariff driven customer grid defections-Techno-economical risks for DSO?. 25th International Conference on Electricity Distribution. http://dx.doi.org/10.34890/846 (accessed 19 June 2019).

LeBel, M., Weston, F., Sandoval, R., 2020. Demand Charges: What Are They Good For? An Examination of Cost Causation 41. https://www.raponline.org/knowledge-center/ demand-charges-what-are-they-good-forl (accessed 20 January 2021).

Mastropietro, P. (2019). Who Should Pay to Support Renewable Electricity? Exploring Regressive Impacts, Energy Poverty and Tariff Equity. Energy Research \& Social Science, 56, 101222. https://doi.org/10.1016/j.erss.2019.101222.

Morell Dameto, N., Chaves-Ávila, J. P., \& Gómez San Román, T. (2020). Revisiting Electricity Network Tariffs in a Context of Decarbonization, Digitalization, and Decentralization. Energies, 13(12), 3111. https://doi.org/10.3390/en13123111.

Nijhuis, M., Gibescu, M., \& Cobben, J. F. G. (2017). Analysis of Reflectivity and Predictability of Electricity Network Tariff Structures for Household Consumers. Energy Policy, 109, 631-641. https://doi.org/10.1016/j.enpol.2017.07.049.

NordREG, 2015. Tariffs in Nordic Countries-survey of Load Tariffs in DSO Grids. http:// www.nordicenergyregulators.org/wp-content/uploads/2015/03/Tariffs-in-Nordic-countries-survey-of-load-tariffs-in-DSO-grids.pdf (accessed 22 January 2021).

OECD, 2011. Regulatory Policy and Governance: Supporting Economic Growth and Serving the Public Interest. OECD. https://www.oecd-ilibrary.org/governance/regulatory-policy-and-governance_9789264116573-en (accessed 20 January 2021).

Ofgem, 2019a. Introduction on Access and Forward-looking charges significant code review. https://www.ofgem.gov.uk/system/files/docs/2019/09/111_-_working_paper_-_summer_2019__ intro_note_final.pdf (accessed 12 December 2019).

Ofgem, 2019b. Targeted Charging Review: Decision and Impact Assessment. https://www. ofgem.gov.uk/system/files/docs/2019/12/full_decision_doc_formatted_updated9.pdf (accessed 26 November 2019).

Ofgem, 2018. Reform of Network Access and Forward-looking Charges Ofgem. https:// www.ofgem.gov.uk/electricity/transmission-networks/charging/reform-network-access-and-forward-looking-charges (accessed 30 November 2020).
Passey, R., Haghdadi, N., Bruce, A., \& MacGill, I. (2017). Designing More Cost Reflective Electricity Network Tariffs With Demand Charges. Energy Policy, 109, 642-649. https:// doi.org/10.1016/j.enpol.2017.07.045.

Pérez-Arriaga, I.J., 2016. Utility of the Future. An MIT Energy Initiative Response to an Industry in Transition. http://energy.mit.edu/wp-content/uploads/2016/12/Utility-ofthe-Future-Full-Report.pdf (accessed 7 March 2019).

Pérez-Arriaga, I. J. (Ed.). (2014). Electricity Tariffs, in: Regulation of the power sector. Springer Science \& Business Media. Springer, London. https://doi.org/10.1007/978-1-44715034-3.

Reneses, J., Rodriguez, M. P., \& Pérez-Arriaga, I. J. (2013). Electricity tariffs. In Regulation of the Power Sector (pp. 397-441). Springer, London.

Pollitt, M. (2018). Electricity network charging in the presence of distributed energy resources: principles, problems and solutions. Economics of Energy and Environmental Policy, 7(1). https://doi.org/10.5547/2160-5890.7.1.mpol.

Prettico, G., Flammini, M.G., Andreadou, N., Vitiello, S., Fulli, G., Masera, M., 2019. Distribution System Operators Observatory 2018: Overview of The Electricity Distribution System in Europe. European Commission. Joint Research Centre.

Regalini, E., 2019. Capcity-based Network Tariffs for Italian Electricity Households. https:// www.ceer.eu/documents/104400/-///c2310057-9124-4708-8f56-6a587f76f569 (accessed 20 January 2021).

Ortega, M. P. R., Pérez-Arriaga, J. I., Abbad, J. R., \& González, J. P. (2008). Distribution Network Tariffs: A Closed Question?. Energy Policy, 36(5), 1712-1725. https://doi. org/10.1016/j.enpol.2008.01.025

Schittekatte, T., \& Meeus, L. (2018). Introduction to Network Tariffs and Network Codes for Consumers, Prosumers, and Energy Communities. https://doi.org/10.2870/934379.

Siano, P. (2014). Demand Response and Smart Grids-A survey. Renewable and Sustainable Energy Reviews. 30(1), 461-478. https://doi.org/10.1016/j.rser.2013.10.022.

Simshauser, P. (2016). Distribution Network Prices and Solar PV: Resolving Rate Instability and Wealth Transfers Through Demand Tariffs. Energy Economics, 54, 108-122. https:// doi.org/10.1016/j.eneco.2015.11.011.

Strielkowski, W., Štreimikiené, D., \& Bilan, Y. (2017). Network Charging and Residential Tariffs: A Case of Household Photovoltaics in the United Kingdom. Renewable and Sustainable Energy Reviews, 77, 461-473. https://doi.org/10.1016/j.rser.2017.04.029.

\section{ANNEX}

This Annex describes current and planned distribution tariffs in some European countries.

\subsection{UNITED KINGDOM}

In the UK, there are two approaches to setting network tariffs, depending on the voltage level at which the network user is connected: extra-high voltage (EHV - above $33 \mathrm{kV}$ ) or medium voltage (MV below $33 \mathrm{kV}$ ).

EHV users pay a time-independent contracted capacity charge and a seasonally fluctuating energy charge. Tariff calculation is based on a nodal load flow model, which has the advantage of being able to calculate individual and cost-reflective charges that take into account network spare capacity.

At the MV level, tariff calculation is simpler and can be characterized as a combination of agreed capacity and time-of-use charges, which vary, depending on the customer category. Domestic consumers face ToU energy charges and fixed charges. 
In all cases, network tariffs are different across the 14 DSO regions, and in some cases, the time blocks also differ between regions, reflecting the underlying cost drivers. However, given that many households do not have smart meters, or do not have ToU charges, the benefits of cost reflective charges are dampened (CEER, 2020).

Ofgem, the UK regulator, is currently reviewing the tariff design in order to make tariffs more cost reflective. Some of the issues under review are improving locational accuracy of distribution charges, analysing other design options for distribution and transmission charges, and linking electricity network tariffs with the procurement of flexibility services from customers to DSOs (Ofgem, 2018).

\subsection{ITALY}

In Italy, a gradual tariff reform took place between 2015 and 2017. Network tariffs were modified from progressive volumetric energy charges, i.e. the charge per $\mathrm{kWh}$ of consumed electricity increased with the growing amount of total electricity consumed during the billing period, to a three-component structure tariff (fixed charge + contracted capacity charge + non-progressive energy charge).

More recently, the regulator has proposed introducing a special tariff for customers who recharge their electric vehicle (EV) at home, in order to accommodate domestic EV charging within the existing electricity contracts. This is possible due to the high penetration and advanced functionality of smart meters in Italy. Around $90 \%$ of household contracts for electricity supply are based on a contracted capacity of $3 \mathrm{~kW}$. If a customer needs additional capacity, increasing contracted capacity requires a one-time payment of around $60 € / \mathrm{kW}$ as a connection charge, and an increase in the yearly network capacity charge of around $25 € / \mathrm{kW}$. The proposal of the regulator to facilitate EV home-charging would increase the maximum allowed capacity during off-peak hours, i.e. night hours (from 23:00 to 7:00), and Sundays and holidays. The new allowed off-peak capacity would not require customers to change their contracted capacity, and the tariff paid by the customer would therefore remain unchanged. The proposal, which received mainly positive feedback from stakeholders, would increase the general contracted capacity, known as "technically available capacity" to $6.0 \mathrm{~kW}$ (instead of $3 \mathrm{~kW}$ ), and therefore allow for a full battery recharge, of around 40 $\mathrm{kWh}$, during the 8-hour night period (CEER, 2020; Regalini, 2019).

\subsection{BELGIUM}

In Belgium, small consumers and businesses currently face ToU energy charges to recover network costs. A planned reform aims to add a capacity charge in the network tariff for these types of consumers. Large consumers already face capacity and energy charges (EU-Universal project, 2020).

\subsection{FRANCE}

In France, time-of-use energy charges and variable-peak charges have been implemented for network users connected at different voltage levels. Their purpose is to incentivize daily peak and seasonal peak shav- ings. Coupled with controlled water heating, these tariffs have shifted about $10 \mathrm{GW}$ of consumption from morning peak hours to night offpeak hours. It has to be noted that these benefits were observed many years after their implementation, illustrating the need to anticipate tariff design reforms with a long-term view.

For medium voltage network users, network charges are differentiated in five time-blocks: annual peak, high season peak, high season offpeak, low season peak, low season off-peak. Annual peak time-block hours may be fixed, or variable, depending on the option selected by the user:

- Fixed time-block hours are defined on ex-ante estimated peak hours: 2 hours during morning peak, 2 hours during evening peak, Sunday excluded, from December to February; and

- Variable time-block hours which correspond to the critical hours of the national capacity mechanism: 10 hours during the 10 to 15 days of peak demand triggered on a day-ahead basis by the TSO.

For low voltage network users, new network tariffs were introduced in 2014, with five time-block energy charges, with one of the time periods, the annual peak period, being defined by the DSO. The main goal was to signal peak demand periods at the local level, while continuing the daily peak shaving through ToU energy charges. The network company is responsible for fixing the 16 daily peak hours at the local level; and the high season which lasts five months, also at the local level (CEER, 2020).

\subsection{GERMANY}

In Germany, current low voltage (LV) tariffs consist of two components: a capacity charge, either fixed or based on maximum demand, and an energy charge. While customers with no load profile metering, i.e. with traditional meters, are subject to fixed charges, those customers with load profile metering are subject to maximum demand charges. Network charges are set by each DSO, based on their costs structure and under NRA supervision, so tariffs can differ from one DSO to another. Since LV household smart meters are not deployed, any temporal granularity on electricity tariffs cannot be implemented yet (EU-Universal project, 2020).

\subsection{NORWAY}

In Norway, tariffs for customers with less than $100 \mathrm{~kW}$ power consumption are predominantly volumetric energy charges. For a typical household, two thirds of the network tariff consists of an energy charge, while one third is a fixed charge. In February 2020, the national regulator proposed a shift to a tariff model which is primarily based on an energy charge, equal to the cost of marginal losses, when the available network capacity is sufficient to transport the expected energy flows. At instances when network capacity is expected to be constrained, DSOs may implement ToU energy charges to incentivize reduction of consumption in those time blocks. This means that consumers would face higher charges when the network is stressed. The remaining network residual costs will be covered through a contracted capacity charge. This charge will, in practice, be fixed in the short-to-medium term but 
can be affected by lasting customer responses, either increasing contracted capacity through adoption of EV or heat pumps (HP), or decreasing contracted capacity through load shifting or investing in storage technologies. Thus, consumers also have an incentive to optimize the long-term use of the grid in accordance with their actual willingness to pay for the network service. Contracted capacity could also be time differentiated, to ensure that consumers utilizing the network in constrained hours pay a higher share of the network costs (CEER, 2020).

\subsection{SPAIN}

In Spain, for small customers with a maximum $15 \mathrm{~kW}$ of contracted capacity, network costs are mostly recovered through a contracted capacity charge $(€ / \mathrm{kW}$ month) and a ToU energy- charge with 3 time-blocks in the year. Network costs are allocated to the different time blocks according to the proportion of peak hours in each time block. In 2021, a new methodology will be adopted for these small customers, with a higher time granularity. It consists of 2 differentiated time blocks for the contracted capacity charge and 3 time-blocks for the energy charge. In Spain, the system wide smart meter deployment has already been completed even for residential customers (CNMC, 2020).

\subsection{DENMARK}

In Denmark, network costs are recovered through an energy charge and a fixed charge. Cost allocation depends on each DSO, as long as requirements imposed by the Danish Electricity Act are met. The NRA only sets the total allowed revenue for each DSO, but does not decide how tariffs are structured.

The tariff regime for DSOs in Denmark has not changed much in recent years. The overall principles for DSO tariffs have remained the same.
However, in June 2020 the Danish government published recommendations for a future tariff design for DSOs in the electricity sector. The purpose of the work was to identify potential for a more cost-reflective tariff structure and give recommendations for changes in the law to support this. The recommendations are mostly overarching principles and guidelines for a future tariff design and not concrete laws or regulations for a new tariff regime.

The Danish TSO/Energinet is also in the process of developing a suggestion for a future tariff design in Denmark for the Danish electricity DSOs and TSO. The Danish Energy Association has announced a new model for tariffs (Tarifmodel 3.0), which is currently being reviewed and proceeded by the Danish Utility Regulator.

The Danish Utility Regulator must approve the new tariff methods.

\subsection{PORTUGAL}

In Portugal, small customers with less than $20.7 \mathrm{kVA}$ of maximum network capacity face a single contracted capacity charge and ToU energy charge, with one to three time-blocks, depending on the consumer's choice. A pilot project developed by the NRA (ERSE) and Energias de Portugal Distribuição (EDPD) aims to test an innovative network tariff scheme for customers at MV, HV, and EHV levels. This pilot will test a tariff with five different time blocks: super-peak, peak, medium, valley and super-valley. Additionally, the same day cannot contain more than four time-blocks, avoiding the coincidence of super-peak and peak time blocks on the same day. This tariff scheme presents a regional differentiation of the time blocks according to the 6 different network areas. In terms of seasonality, the time-blocks are defined, throughout the year, separated into three seasons, covering different months, depending on the network areas (EDP Distribuçao, 2020; ERSE, 2018). 